\title{
Análise de Conforto Urbano do Marco das Três Fronteiras em Foz Do Iguaçu-PR
}

Helenice M. Sacht ${ }^{1}$ | Herlander Mata-Lima ${ }^{2}$ | Andréa de Oliveira Cardoso ${ }^{3}$ | Jair Stivenz C. Delgado 4 Recibido: 15-05-2019 | en su versión final: 01-06-2020

Resumo

\begin{abstract}
O desenho urbano bioclimático aborda, desde sua concepção, o clima como uma variável importante, sendo a análise climática um instrumento imprescindível para intervenções urbanas. A pesquisa realizada tem como objetivo a caracterização de estratégias bioclimáticas para projetos urbanos em Foz do Iguaçu, tendo como base a caracterização climática do local, o levantamento das diretrizes e soluções condizentes com o clima. Analisaram-se estratégias bioclimáticas tendo como referência os documentos normativos nacionais e ferramentas específicas de análise urbana. Como aplicação, realizou-se um estudo de caso no Marco das Três Fronteiras aplicando as diretrizes adequadas ao clima com subsídio de um diagnóstico baseado em condições de temperatura e umidade. A pesquisa permitiu estabelecer parâmetros de conforto térmico e estratégias bioclimáticas para projetos urbanísticos adequados ao clima de Foz do Iguaçu-PR, clima ainda não estudado nesse aspecto.
\end{abstract}

Palavras-chave: projetos urbanos; estratégias bioclimáticas; clima urbano; tríplice fronteira

Citación

Sacht, H.M. et al. (2020). Análise de conforto urbano do marco das Três Fronteiras em Foz do Iguaçu-PR. ACE: Architecture, City and Environment, 15(43), 8295 DOI: http://dx.doi.org/10.5821/ace.15.43.8295

\section{Urban comfort analysis of the Three Borders Landmark in Foz do Iguaçu-PR}

Abstract

\begin{abstract}
The concept of bioclimatic urban design addresses the micro-climate as an important variable so that climate analysis is an essential tool in the implementation study of urban intervention projects. Therefore, this research project aims to survey and characterize bioclimatic strategies for urban projects in Foz do Iguaçu, based on local climatic characterization and, guidelines set according to climate conditions. Bioclimatic strategies were analyzed based on the national norms and specific tools of urban analysis. A case study was carried out in the Marco das Três Fronteiras applying the appropriate climate guidelines with a diagnosis based on temperature and humidity conditions. At the end of the research thermal comfort parameters and bioclimatic strategies suitable with urban projects suitable were established for the climate of Foz do Iguaçu-PR, climate not yet studied in this respect.
\end{abstract}

Keywords: urban projects; bioclimatic strategies; urban climate; three borders

\footnotetext{
${ }^{1}$ Doutora, Universidade Federal da Integração Latino-Americana - UNILA (ORCID ID: 0000-0002-4674-9629, Wos Researcher ID: H-5988-2016), ${ }^{2}$ Doutor, Universidade Federal da Integração Latino-Americana - UNILA

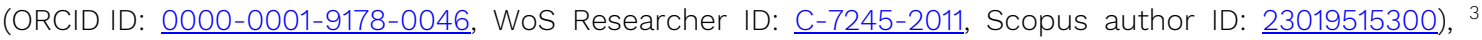
Doutora, Universidade Federal do ABC (ORCID ID: 0000-0001-9914-7501, Researcher ID: E-6651-2019), ${ }^{4}$ Graduando em Engenharia Civil de Infraestrutura, Universidade Federal da Integração Latino-Americana UNILA. E-mail de contato: helenice.sacht@unila.edu.br
}

ACE, 15 (43) CC BY-ND 3.0 ES | UPC Barcelona, España Análise de conforto urbano do marco das Três Fronteiras em Foz do Iguaçu-PR. DOI: http://dx.doi.org/10.5821/ace.15.43.8295 


\section{Introdução}

Desde a Antiguidade, os espaços urbanos tiveram grande importância e, mesmo sendo ambientes externos, as condições de conforto são imprescindíveis (Gomez, Gil \& Jabaloyes, 2004), sendo o estudo do clima fundamental para atingir condições de conforto, visto que influencia diretamente os fatores determinantes no momento de fazer as concepções arquitetônicas e construtivas (Moonen, et al., 2016). Assim, o atual crescimento demofórico (populacional+industrial) torna ainda mais essencial a análise dos elementos do clima, destacando-se a temperatura, o vento, a umidade e as precipitações.

O meio urbano, dependendo de suas características de configuração e capacidade térmica das estruturas, estabelece condições preferenciais para a ocorrência do fenômeno de ilha de calor, que além afetar o conforto térmico, pode favorecer a ocorrência de chuvas intensas e localizadas (Olgyay, 1963, Assis, 2006; Vemado \& Pereira Filho, 2016; Maia, Pinto, \& Lima, 2017). Em contrapartida, a vegetação em um meio urbano pode causar um efeito de resfriamento, diminuindo a absorção de radiação solar por sombreamento e evapotranspiração, amenizando o microclima da vizinhança (Duarte, et al., 2015; Toparlar et al., 2017). Conhecer as condições específicas de conforto térmico para cada clima e tipo de moradia, favorece o projeto de edifícios mais habitáveis. Expressar essas condições em função da temperatura e da umidade relativa, facilita para os arquitetos estabelecer uma relação entre as condições de conforto com estratégias passivas de acondicionamento ambiental de edificios (Marincic, Ochoa, Río, 2012).

São muitos os estudos relacionados ao clima e sua influencia nas questões de planejamento e desenho urbano. Muitos deles analisam as mudanças climáticas e ilhas de calor. O estudo realizado por Arellano, Roca e Batlle (2018) propõem a construção de um conjunto de modelos explicativos para as ilhas de calor urbanas da Região Metropolitana de Barcelona, com o objetivo de auxiliar os planejadores a tomar medidas que sirvam para mitigar os efeitos das mudanças climáticas no nível do planejamento territorial e urbano. Com o uso de técnicas de sensoriamento remoto e medidas "in loco", foi avaliado como o design urbano afeta a geração de ithas de calor, bem como o microclima urbano em geral.

Salvati, Coch Roura e Cecere (2016) realizaram um estudo com o objetivo de avaliar a precisão um modelo denominado "Urban Weather Generator" (UWG), desenvolvido para gerar arquivos climáticos urbanos a partir de dados climáticos rurais, a fim de melhorar a precisão das simulações de energia do edifício no contexto urbano. As previsões do modelo foram comparadas com observações reais em diferentes locais urbanos em Roma e Barcelona. As comparações foram realizadas para um ano de observações para cada local, focando a análise nos meses de verão e inverno. Observou-se que o modelo UWG é capaz de capturar a tendência geral da temperatura urbana. A precisão da previsão aumenta para locais urbanos localizados em um tecido urbano bastante homogêneo em termos de densidade de edifícios e cobertura vegetal. Nessas situações, o modelo permite uma boa previsão das temperaturas do ar urbano com baixos requisitos computacionais e pode ser uma ferramenta útil para melhorar a precisão da análise da energia urbana.

Há ainda pesquisas cujo foco é o desempenho ambiental dos espaços urbanos, com o uso dos vários elementos da paisagem para alcançar o conforto térmico de seus usuários. O estudo de Saeed, Azmy e Omar (2018), por exemplo, apresenta uma parte teórica que identifica os vários desempenhos dos elementos da paisagem e uma parte analítica na qual o Campus Médico de Tanta foi selecionado para um estudo de caso. No estudo foi realizada uma avaliação do efeito do projeto proposto, de forma a obter o melhor desempenho ambiental dos espaços urbanos, utilizando o software de simulação ambiental ENVI-MET. Os resultados comprovam o papel dos elementos da paisagem em

ACE, 15 (4:3) CC BY-ND 3.0 ES | UPC Barcelona, España | Análise de conforto urbano do marco das Três Fronteiras em Foz do Iguaçu-PR. DOI: http://dx.doi.org/10.5821/ace.15.43.8295 
melhorar o desempenho ambiental, diminuir a temperatura do ar, reduzir a temperatura radiante média e a temperatura da superfície.

Outro estudo analisa a relação entre as características físicas dos parques urbanos e seus efeitos do resfriamento em pequena escala em dois parques urbanos da cidade de Barcelona: o Turó Parc e o Parc del Centre del Poblenou. O estudo foi realizado com base em medições, sensoriamento remoto e simulação térmica, registrando variáveis micrometeorológicas no interior e no entorno dos parques durante o dia e a noite em um dia de verão. Observou-se que a vegetação exerceu a maior influência nas temperaturas. As primeiras abordagens destacam o potencial das características de projeto e localização na otimização do efeito ilha fria para ajudar a reduzir o aquecimento nas cidades (GARCIAHARO e ARELLANO, 2018).

O ecossistema da cidade envolve variáveis ambientais que modificam as características físicas do espaço urbano, considerando que o clima e a forma urbana definem uma infinidade de combinações no espaço e no tempo. As interações se verificam em múltiplos níveis; por exemplo, o clima afeta diretamente espaços construídos e o homem, e estes, por sua vez, modificam o clima (Unger, 1995; Gomez, Tamarit \& Jabaloyes, 2001). Para incluir esses fatores em projetos urbanos, deve-se considerar que cada local apresenta diferentes tipos de clima, cuja análise implica determinar uma série de estratégias e mecanismos diferentes que levem a uma melhor interação com o ambiente (Flor \& Domínguez, 2004). As características do clima influenciam diretamente na ocupação dos espaços urbanos, e isso não é diferente para o caso do Marco das Três Fronteiras localizado no município de Foz do Iguaçu, no estado do Paraná (PR), Brasil.

A adoção dos princípios bioclimáticos para desenho urbano requer em primeiro lugar uma avaliação da região climática, que pode ser feita a partir das variações da temperatura do ar, da amplitude dessas variações, dos regimes de chuvas que determinam as estações secas ou chuvosas, da intensidade da radiação difusa e direta, da quantidade de umidade relativa, do regime dos ventos, da altitude e da localização geográfica. Com base nesta avaliação, devem ser analisadas as porções do espaço urbano, uma vez que existem situações diferenciadas dentro da estrutura espacial, com a ocorrência de diferenças entre os elementos do clima (temperatura, ventos e umidade) nos diferentes bairros, ruas, praças, lagoas, entre outros (Romero, 2000).

No contexto de estratégias bioclimáticas em desenho urbano, a otimização do ambiente interno é um dos objetivos mais importantes da arquitetura. Sua realização depende de um profundo conhecimento do clima e de seus efeitos sobre os elementos construídos (Kapsomenakis, et al., 2013). Isso quer dizer que o fato de se construir novos edifícios modifica o clima exterior. Além disso, tais mudanças no exterior pelas construções sem planejamento sustentável acarretam um novo ambiente com condições climáticas diferentes, que vão reduzindo as sensações de conforto. Assim, partindo do desenho de um projeto e sua execução, o projetista será responsável não só pelas condições internas da construção, mas também pela alteração no ambiente exterior. Com base nisso, é imperativo que se considerem os elementos ambientais maiores (e.g., a radiação solar, temperatura do ar, velocidade do ar e umidade relativa) e menores (e.g., elementos térmicos e do ar, a absorção, a reflexão, a evaporação e a condensação) que estão na conformação do clima urbano ou local (Romero, 2007; Higueras, 2006, Musy, et al., 2015).

O clima urbano é influenciado pelos materiais constituintes da superficie urbana, que se diferencia dos materiais das superficies não construídas. Os materiais urbanos possuem uma capacidade térmica mais elevada que a dos materiais das áreas do entorno e são melhores condutores. A superficie urbana apresenta um aspecto mais rugoso que as superficies não construídas, ocasionando uma maior fricção entre a superficie e os ventos que a atravessam. Ao mesmo tempo, as superficies das edificações atuam como refletoras e radiadoras que, em seu conjunto, aumentam

ACE, 15 (4:3) CC BY-ND 3.0 ES | UPC Barcelona, España | Análise de conforto urbano do marco das Três Fronteiras em Foz do Iguaçu-PR. DOI: http://dx.doi.org/10.5821/ace.15.43.8295 
os efeitos da radiação incidente (Romero 2007). Para projetos urbanos, a autora salienta ainda que elementos urbanos como a orientação das ruas e em relação à direção dos ventos, o tamanho, a altura e a densidade dos edificios, assim como a distribuição dos edificios em termos de altura, entre outros fatores têm grande impacto nas condições de temperatura e vento. Todos esses aspectos, portanto, devem ser observados em projetos de adequação em relação ao clima.

Portanto, o clima de qualquer lugar é afetado pelos diferentes níveis de densidade das construções e altura (e sua heterogeneidade) dos edifícios próximos, pois as características do ambiente construído exercem influência determinante no albedo (Yang \& Li, 2015). Além disso, quando as construções não são planejadas de tal forma que tenham uma interação ótima com o ambiente, desencadeia-se a denominada itha de calor na área urbana, que se manifesta pelo aumento da temperatura do ar comparativamente às regiões menos urbanizadas, sobretudo no período da noite. O crescimento demofórico contribui para a formação da itha de calor, visto que altera substancialmente as características do espaço urbano pela redução das áreas verdes, ocupação do ambiente urbano por obras de concreto e asfalto que alteram o albedo, poluição industrial e circulação de automóveis (Monteiro, 1976).

Com base nos aspectos supramencionados, a presente pesquisa visa inventariar, caracterizar e estabelecer estratégias bioclimáticas, para projetos urbanos adequados ao clima da cidade de Foz do Iguaçu-PR, localizada ao sul entre os trópicos de capricórnio e câncer, que apresenta um clima subtropical quente-úmido. Mediante essas estratégias busca-se uma boa interação entre homem, ambiente e espaços urbanos, de forma a possibilitar o desenvolvimento de projetos que aproveitem e garantam condições de conforto adequado aos usuários dos espaços. Para tal, foi analisado, antes de passar por uma revitalização, o caso do Marco das Três Fronteiras, ponto do qual é possível avistar os países vizinhos da região, Paraguai (Ciudad Del Este) e Argentina (Puerto Iguazú). A cidade de Foz do Iguaçu-PR localiza-se a uma latitude $25^{\circ} 32^{\prime}$ 52"sul e a uma longitude 54 $35^{\prime}$ ' $17^{\prime \prime}$ "oeste e a 164 metros de altitude. Apresenta clima subtropical úmido, com verões quentes, geadas pouco frequentes e chuvas em todos os meses do ano. A região da tríplice fronteira, denominada Região Trinacional, é composta pelos municípios de Puerto Iguazú (AR), Foz do Iguaçu (PR) e Ciudad del Este (PI) e apresenta características climáticas continentais, ou seja, encontra-se distante do oceano, favorecendo a predominância do vento norte/nordeste sobre a região. Esses ventos predominantes são ventos continentais quentes, que passam por várias regiões, trazendo um ar mais quente, por vezes seco e úmido.

Essas características continentais favorecem o território aquecido por longas horas, provocando o desconforto térmico para a população da região. Outro fator predominante é o contingente hídrico na região, que junto aos demais fatores meteorológicos ajudam na alta umidade, elevando a sensação térmica local, que são percebidas pela população, em dias de forte calor. Essa região Trinacional do Iguaçu foi modernizada, de forma a atender principalmente a demanda turística; recebeu infraestrutura viária com a construção das pontes que interligam os três países; sofreu uma explosão demográfica, ocasionada, sobretudo, pela construção da Hidrelétrica de Itaipu e pelas oportunidades oferecidas pelo comércio de fronteira. Desse modo, vários grupos étnicos, de diversas partes do mundo, vieram se somar aos que já haviam se fixado no local em épocas coloniais (Santos, 2015).

\section{Metodologia}

O desenvolvimento da pesquisa seguiu as seguintes etapas abaixo descritas: Revisão Bibliográfica; Análise climática de Foz do Iguaçu-PR; Necessidades térmicas e levantamento de estratégias bioclimáticas para projetos urbanos; Realização de estudo de caso referente ao Marco das Três Fronteiras.

ACE, 15 (4.3) CC BY-ND 3.0 ES | UPC Barcelona, España | Análise de conforto urbano do marco das Três Fronteiras em Foz do Iguaçu-PR. DOI: http://dx.doi.org/10.5821/ace.15.43.8295 


\subsection{Revisão Bibliográfica}

A revisão bibliográfica baseou-se na pesquisa em livros técnicos, artigos técnicos, boletins técnicos e publicações online de institutos de pesquisa e universidades e demais conhecimentos disponíveis em redes de informação por computador. A pesquisa foi focada nos temas relacionados ao desenvolvimento de projeto urbano e a inserção de aspectos bioclimáticos, contemplando o estudo de normas e parâmetros norteadores, levantamento e estudo de soluções passivas para projetos urbanos adequados ao clima e pesquisa e caracterização de metodologias e aplicação de estratégias destinadas ao contexto urbano. Essas informações visaram aprofundar importantes conceitos apresentados na Introdução e embasamento teórico para o desenvolvimento metodológico e discussão dos resultados.

\subsection{Análise Climática de Foz do Iguaçu-PR}

A análise dos dados climáticos de uma localidade é a base para a inserção de princípios do conforto ambiental em várias fases do desenvolvimento de projetos. A abordagem de análise climática para implantação de edificações e intervenções urbanas extrapola a ciência da climatologia, pois exige o levantamento de outros aspectos, tais como a fisiologia humana e a capacidade de adaptação dos usuários a diferentes condições climáticas. Esse tipo de análise deve subsidiar a tomada de decisão, a seleção das variáveis ambientais locais que afetam o projeto, bem como de métodos ou procedimentos de aplicação de resultados em cada etapa do projeto, seja ele urbano ou de edifícios.

A análise climática de Foz do Iguaçu-PR foi a base para determinação de estratégias destinadas a projetos urbanos e foi realizada primeiramente com base na classificação climática de KöppenGeiger; seguidamente foi utilizado o programa Climate Consultant 6.0 para analisar os dados climáticos e indicar soluções construtivas/ urbanas de acordo com o clima.

\subsubsection{Análise Climática com Base na Classificação Climática de Köppen-Geiger e Normais Climatológicas}

A classificação climática de Köppen-Geiger é o sistema de classificação global dos tipos climáticos, mais utilizada em geografia, climatologia e ecologia. Foi proposta em 1900 pelo climatologista Wladimir Köppen e aperfeiçoada em 1918, 1927 e 1936 com a publicação de novas versões, preparadas em colaboração com Rudolf Geiger. Consiste na divisão do clima mundial em cinco grandes grupos. Os cinco grandes grupos climáticos principais são designados pelas letras iniciais do alfabeto maiúsculas (A, B, C, D e E) e correspondem às regiões fundamentais, do equador aos polos. Essas regiões são divididas em subgrupos, considerando a distribuição sazonal da precipitação acrescida das características da temperatura.

Atualmente, a classificação climática de Köppen continua sendo o sistema mais amplamente utilizado por critérios geográficos e climatológicos em todo o mundo, inclusive no Brasil. Recentemente, Alvares, Stape, Sentelhas, Gonçalves, \& Sparovek (2014) desenvolveram um sistema de informação geográfica para identificar os tipos climáticos de Köppen baseados em dados de temperatura e precipitação de 2.950 estações meteorológicas, obtendo-se um mapa climático final que permite aos usuários interpretar a ocorrência de tipos de clima no Brasil. A ocorrência das zonas climáticas está diretamente relacionada à sua localização quanto à latitude, entre outros fatores, segundo a classificação Köppen 1931.

\subsubsection{Uso do Programa Climate Consultant 6.0}

ACE, 15 (4.3) CC BY-ND 3.0 ES | UPC Barcelona, España | Análise de conforto urbano do marco das Três Fronteiras em Foz do Iguaçu-PR. DOI: http://dx.doi.org/10.5821/ace.15.43.8295 
Climate Consultant 6.0 é um software, baseado em gráficos, que auxilia na compreensão do clima local. Por meio do uso de um arquivo em formato epw, contendo dados do clima, o programa faz a recomendação de estratégias bioclimáticas. O Climate Consultant traduz esses dados climáticos em gráficos para análise do que ocorre em cada clima e faz a indicação de soluções construtivas/ urbanas.

A carta psicrométrica é um dos recursos disponíveis no Climate Consultant. Cada ponto no gráfico representa as temperaturas e a umidade relativa de cada uma das 8.760 horas por ano. Diferentes estratégias de projeto são representadas por zonas específicas nessa carta. A percentagem de horas que se enquadram em cada uma das diferentes estratégias fornece uma ideia das estratégias de aquecimento ou de resfriamento passivo mais eficaz. O Climate Consultant analisa a distribuição dos dados psicrométricos em cada estratégia, de modo a criar uma lista única de diretrizes para um determinado local.

Mesmo que o programa indique estretégias bioclimáticas para edificações, sua possibilidade de análise geral do clima auxilia numa análise inicial, sendo que ainda, há a possibilidade de adaptação das estratégias indicadas para edificações serem adaptadas ao conforto urbano.

\subsection{Levantamento de Estratégias Bioclimáticas para Projetos Urbanos Análise Climática de Foz do lguaçu-PR}

Para cada região existem princípios de desenho urbano que favorecem o conforto ambiental e o desempenho dos espaços construídos. Por exemplo, nas regiões de clima úmido, como é o caso de Foz do Iguaçu, o impacto da radiação difusa deve ser considerado, tanto quanto o da radiação direta para evitar altos índices de refletividade das superfícies construídas. As estratégias bioclimáticas adotadas podem ser contraditórias, porém, a forma e o desempenho das edificações e demais elementos urbanos do entorno são fundamentais, uma vez que o traçado urbano não consegue suprir todas as exigências climáticas da região.

Sabe-se de antemão que, com a finalidade de corrigir, atenuar ou mudar certas variáveis do clima, pode utilizar-se vegetação, água, anteparos, revestimentos, cores, materiais diversos etc.; contudo, são as características do meio que prevalecem. Além das diretrizes propostas por Romero (2000; 2007), mediante a aplicação de metodologias destinadas ao contexto urbano, existem ainda outras metodologias, como a proposta anteriormente por Katzschner (1997). Com base nessas informações foram selecionadas algumas diretrizes com potencial de aplicação em projetos urbanos desenvolvidos em Foz do Iguaçu-PR.

\subsection{Estudo de Caso Referente ao Marco das Três Fronteiras em Foz do Iguaçu-PR}

O Marco das Três Fronteiras foi escolhido para estudo de caso, pois se trata de um local emblemático que marca geograficamente a fronteira de Foz do Iguaçu-PR (Brasil) com as cidades vizinhas de Puerto Iguaçu (Argentina) e Cidade del Este (Paraguai). Em cada uma das cidades foi construído um obelisco, símbolo da igualdade, complementaridade e respeito entre as três nações. O marco Brasileiro, construído em pedra e cimento e pintado com as cores nacionais, estabelecem o limite territorial e a soberania do Brasil. Localizado a $6 \mathrm{~km}$ do centro da cidade, o Marco brasileiro foi inaugurado em 20 de julho de 1903 por uma Comissão Estratégica dos países (a demarcação dos países está nas margens dos rios Iguaçu e o rio Paraná).

Esta área tem uma grande vegetação de Mata Atlântica que está presente em 97\% do estado do Paraná. Caracteriza-se pela presença de árvores de médio e grande porte, formando uma floresta

ACE, 15 (4.3) CC BY-ND 3.0 ES | UPC Barcelona, España | Análise de conforto urbano do marco das Três Fronteiras 6 em Foz do Iguaçu-PR. DOI: http://dx.doi.org/10.5821/ace.15.43.8295 
fechada e densa, com uma rica biodiversidade e as árvores de grande porte formam um microclima na mata, proporcionando sombra e umidade. Dentre os espaços ao ar livre visitados na cidade de Foz do Iguaçu, tratava-se, na época, de um dos menos visitados em termos de atividade turística. Por este motivo, surgiu a ideia de analisá-lo para estabelecer uma relação entre as condições climáticas do local (microclima) e a baixa visitação e, com base nisso, indicar estratégias bioclimáticas que proporcionem melhores condições de conforto urbano, dentre as indicadas para o clima de Foz do Iguaçu, anteriormente estudadas.

Para uma análise mais detalhada do microclima local, foram necessárias a execução de medições de temperatura e umidade com um equipamento denominado Termo-Higro-Decibelimetro-Luximetro, modelo THDL 400, Instrutherm. Em um só instrumento são incorporadas quatro diferentes ferramentas, porém as utilizadas foram o termômetro, que pode ser utilizado tanto em graus célsius de $-20^{\circ} \mathrm{C} \sim 750^{\circ} \mathrm{C}$ e em graus Fahrenheit de $-4^{\circ} \mathrm{F} \sim 1400^{\circ} \mathrm{F}$ com uma precisão de (+/-) 3\% da leitura e o higrômetro que registra a umidade relativa entre 25\% 95\% RH com uma precisão de (+/-) 5\% de $\mathrm{RH}$.

Após a coleta de dados foi elaborado um conjunto de gráficos por meio do software Surfer 12, (sua função é reunir valores encontrados numa determinada área, tais como curvas de níveis de um terreno, entre outros exemplos, por uma planilha de dados com coordenadas x, y e z. Através de uma coordenada estabelece-se um ponto de referência. O conjunto de pontos é interpolado resultando em gráficos com curvas delimitando zonas), onde se obtém informações sobre as condições do local durante um determinado período. Para o estudo das condições de conforto urbano (térmico) do Marco das Três Fronteiras, foram selecionados cinco pontos de medição (Figura 1), determinados de acordo com a maior frequência de permanência de usuários no local. Para tais pontos, foram medidos temperatura e umidade relativa do ar em horários pré-estabelecidos.

Figura 1. Distribuição espacial dos locais de medição das variáveis climáticas para o Marco das Três Fronteiras antes da Restauração

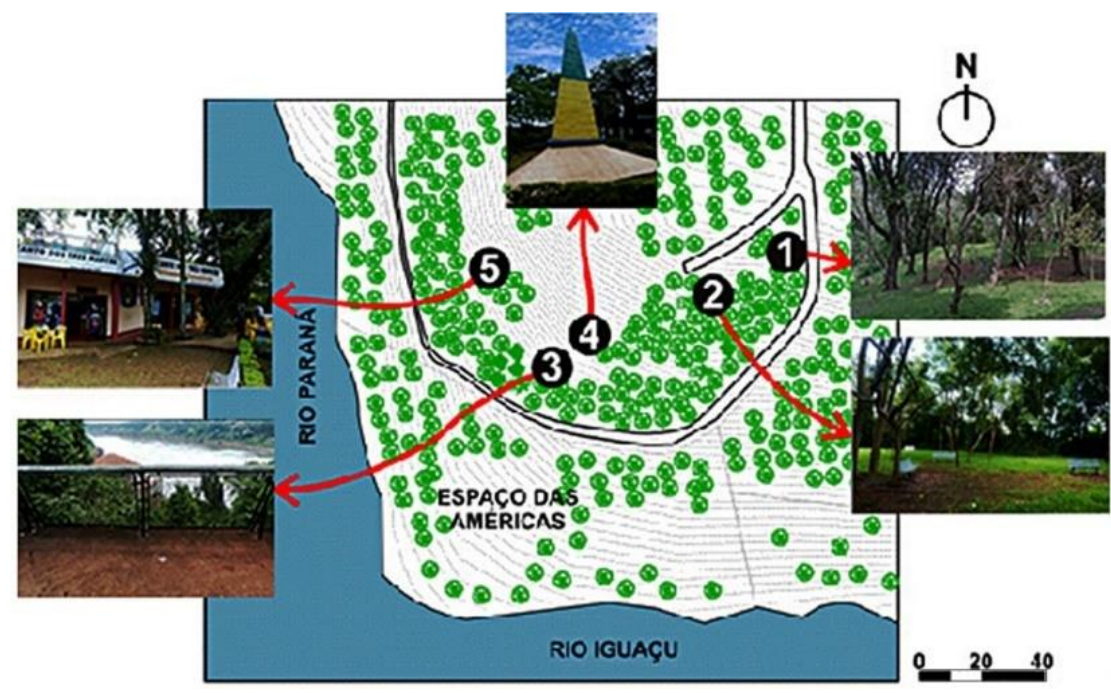

Fonte: Elaboração própria.

Com o auxílio de dados do aparelho GPS (Sistema de Posicionamento Global), foram obtidas as coordenadas planas do sistema UTM (Universal Transversa de Mercator) de cada ponto e os mesmos marcados num plano inicial e posteriormente nos pontos de medição. As coordenadas foram

ACE, 15 (4.3) CC BY-ND 3.0 ES | UPC Barcelona, España | Análise de conforto urbano do marco das Três Fronteiras em Foz do Iguaçu-PR. DOI: http://dx.doi.org/10.5821/ace.15.43.8295 
utilizadas na espacialização dos pontos para a confecção dos cartogramas. As coordenadas UTM dos pontos de medição são: Ponto 01 (Parque) Sul 7167507.02, Leste 742079.09; Ponto 02 (Bancos) Sul 7167501.10, Leste 742062.36; Ponto 03 (Mirante) Sul 7167485.78, Leste 742034.12; Ponto 04 (Marco) Sul 7167494.57, Leste 742036.95; e Ponto 05 (Lanchonete) Sul 7167506.00, Leste 742022.00.

Esses cartogramas foram confeccionados com o auxílio do Surfer 12 Windows® 8.0, utilizando o interpolador Krigagem Ordinária. Na elaboração dos cartogramas de cada dado (temperatura e umidade) usou-se a degradação de cores, sendo tons mais claros para valores mais baixos e mais escuros para valores superiores. Os dados foram coletados no solstício de inverno (21 de junho) de 2015 em condições de tempo atmosférico parcialmente nublado, em dez horários (08h, 09h, 10h, 11h, 12h, 13h, 14h, 15h, 16h e 17h), com o auxílio do equipamento Termo-Hidro-Decibelimetro-Luximetro THDL 400, a uma altura aproximada de 1,00 m em relação ao nível do solo, equivalente ao nível de utilização dos usuários, considerando a posição para desenvolver diferentes atividades. A duração de tempo necessária para completar a medição nos cinco pontos foi cerca de 10 minutos para cada horário. Esse método de medição de variáveis meteorológicas por transecto movél, a partir de uma única coleta diária, tem sido aplicado em estudos de microclima, por exemplo, na investigação da influência de áreas verdes no microclima de áreas adjacentes (Ferreira, Carrilho \& Mendes, 2015).

\section{Resultados e Discussões}

Concluya de forma clara y concisa aportando perspectivas complementarias a las ya discutidas en la sección de resultados.

\subsection{Análise Climática de Foz do lguaçu-PR \\ 3.1.1 Análise Climática-Köppen-Geiger e Normais Climatológicas}

O clima de Foz de Iguaçu é subtropical úmido mesotérmico, classificado por Köppen como "Cfa" (clima temperado úmido com verão quente), que concorda com a classificação atualizada por Alvares et al. (2014), também chamada de Cfa (clima subtropical úmido, oceânico sem estação seca, verão quente), por ser equivalente. O grupo climático " $\mathrm{C}$ " indica clima temperado quente, com temperatura média do ar do mês mais frio compreendida entre $-3^{\circ} \mathrm{C}$ e $18^{\circ} \mathrm{C}$; a temperatura média do mês mais quente maior que $10^{\circ} \mathrm{C}$ e as estações de verão e inverno são bem definidas. A região fundamental "f" indica clima úmido, ocorrência de precipitação em todos os meses do ano; inexistência de estação seca definida e precipitação média do mês mais seco deverá ser superior a $60 \mathrm{~mm}$. A classe climática "a" apresenta verão quente e a temperatura média do ar no mês mais quente devera ser superior a $22^{\circ} \mathrm{C}$.

A cidade (altitude de $192 \mathrm{~m}$ ), tem uma das maiores amplitudes térmica anuais do estado, valor aproximado de $10^{\circ} \mathrm{C}$ de diferença média entre o inverno e o verão, devido a uma menor influência da maritimidade. Por essa razão, os verões costumam ser muito quentes, com máximas médias chegando aos $33^{\circ} \mathrm{C}$, chegando a superar a marca dos $40^{\circ} \mathrm{C}$ em alguns anos. Apesar de serem considerados amenos, os invernos propiciam quedas bruscas de temperaturas que podem cair abaixo de zero durante a passagem de frentes frias com as massas de ar polar. As chuvas costumam ser bem distribuídas durante o ano, com uma pequena redução no inverno. A precipitação anual varia em torno dos $1.800 \mathrm{~mm}$. Através das normais climatológicas disponibilizadas pelo Instituto Nacional de Meteorologia (INMET) é possível verificar o padrão mensal de chuvas e temperatura (Figura 2).

Figura 2. Normais Climatológicas para Foz do Iguaçu-PR

ACE, 15 (4.3) CC BY-ND 3.0 ES | UPC Barcelona, España | Análise de conforto urbano do marco das Três Fronteiras em Foz do Iguaçu-PR. DOI: http://dx.doi.org/10.5821/ace.15.43.8295 


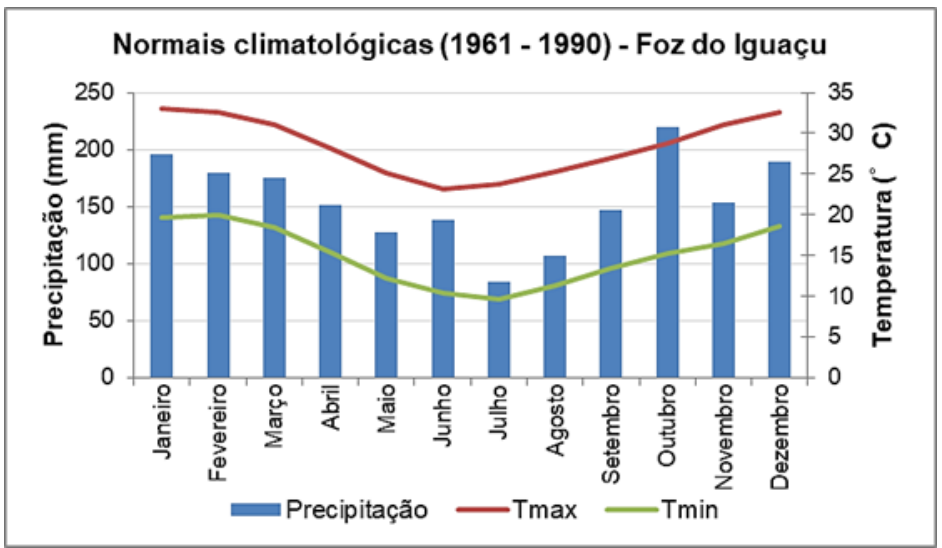

Fonte: Elaborado a partir das Normais Climatológicas (1961 - 1990) do INMET, 2018.

O período mais quente ocorre de novembro a fevereiro, quando a temperatura máxima ultrapassa os 30ㄷ. O período mais frio ocorre entre junho e agosto, com a temperatura mínima atingindo aproximadamente 10 ㅇ em julho. A amplitude térmica diária média, que indica a amplitude média do ciclo diurno, é em torno de 13ํㅡ, atingindo o máximo em novembro 14,5ㄷ e o mínimo em fevereiro 12,5드, representando em média as diferenças entre as temperaturas máximas e mínimas. Em termos do ciclo sazonal, a amplitude térmica anual é cerca de 10ํ para as temperaturas máxima e mínima. Há um padrão de chuva regular ao longo do ano, como ocorre na maior parte da Região Sul do Brasil, sem estações seca e chuvosa bem definidas, havendo uma redução da precipitação nos meses mais frios (julho e agosto), com um mínimo em julho (84 mm) e um máximo em outubro (220 mm), seguido por janeiro (196 mm).

\subsubsection{Análise dos Resultados do Programa Climate Consultant 6.0}

O programa Climate Consultant 6.0 permite analisar as condições de conforto por quatro modelos, sendo eles: Modelo de Conforto do Código de Energia da California 2013 (California Energy Code Confort Model 2013); Modelo da Norma ASHRAE 55 e Manual de Fundamentos; Modelo da Norma ASHRAE 55, Manual de Fundamentos 2005 e Modelo de Conforto Adaptativo - ASHRAE 55, 2010. Tratam-se de modelos americanos. O que se pode descartar de início é a aplicação do modelo de Conforto do Código de Energia da California 2013, por ser específico para uma localidade americana. No presente trabalho foi considerado no Climate Consultant 6.0 - o Modelo de Conforto Adaptativo da Norma ASHRAE 552010 - que é um modelo conceituado na área de conforto ambiental e utilizado internacionalmente, sendo que algumas estratégias inicialmente indicadas para construções foram adaptadas aos espaços urbanos. No modelo de Conforto Adaptativo da Norma ASHRAE 552010 (Adaptative confort model in ASHRAE 55 Standard 2010) são considerados espaços ventilados naturalmente, e considera-se que os ocupantes podem adaptar suas roupas às condições térmicas, e se estão desenvolvendo alum tipo de atividade, variando a taxa metabólica entre 1,0 e 1,3 met.

Nos parâmetros (critérios) do modelo escolhido, podem ser modificados o limite aceitável de conforto (80 a 90\%). No caso de Foz do Iguaçu, baseado nos dados climáticos do arquivo em formato *.epw, a mínima temperatura média mensal exterior é de $14,1^{\circ} \mathrm{C}$ e a máxima temperatura média mensal exterior será de $26,7^{\circ} \mathrm{C}$. A mínima temperatura operativa será de $19,7^{\circ} \mathrm{C}$ e a máxima temperatura operativa de $28,6^{\circ} \mathrm{C}$. Os doze gráficos seguintes sintetizam os resultados da média da temperatura de bulbo seco (pontos amarelos: inferiores a $40^{\circ} \mathrm{C}$ ) e da umidade relativa concorrente (pontos verdes: superiores a 40\%) (Figura 3a). em Foz do Iguaçu-PR. DOI: http://dx.doi.org/10.5821/ace.15.43.8295 
Figura 3. Variação da temperatura de bulbo seco (pontos amarelos: inferiores a 40ㄷ) e umidade relativa (pontos verdes: superiores a 40\%) (a); Carta psicrométrica, para Foz do Iguaçu-PR (b)
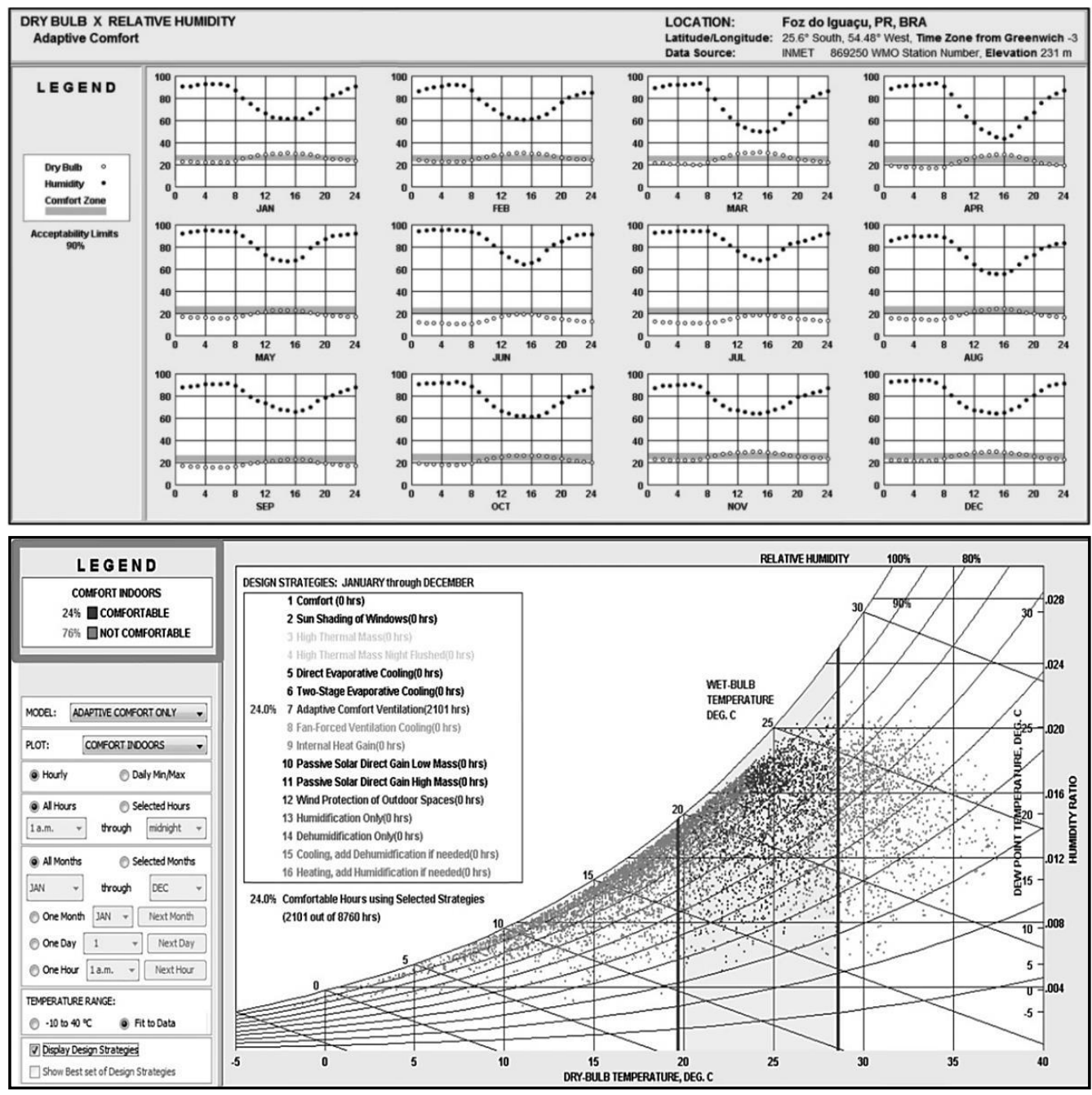

Fonte: Elaboração própria no Programa Climate Consultant 6.0, 2018.

Também é apresentada em cada gráfico mensal, uma linha horizontal espessa, que indica a zona de conforto, tal como mostrados anteriormente na tela de critérios, baseado nos dados climáticos do arquivo *.epw de Foz do Iguaçu. A temperatura de bulbo seco é quase o inverso da umidade relativa. Em boa parte dos meses a temperatura fica fora da zona de conforto, principalmente para os meses de inverno (junho e julho). Durante o verão, dezembro e janeiro, ocorrem altas temperaturas.

Por meio da escolha do modelo de conforto adaptativo foi obtida a carta psicrométrica para Foz do Iguaçu-PR, conforme representada na Figura 3b. A carta psicrométrica relaciona os dados de temperatura (no eixo das abcissas - $x$ ) com a umidade relativa (no eixo das ordenadas - y). A aplicação das estratégias de projeto indicadas permite alcançar um certo grau de conforto. Essa lista de diretrizes para projetos se aplica especificamente ao clima cujo arquivo climático foi analisado, começando com o mais importante.

O que se observa é que diante do rigor do clima de Foz do Iguaçu-PR com temperaturas elevadas no verão e temperaturas mais baixas no inverno, em relação ao conforto adaptativo, o programa indica 
que, sem o uso de sistemas ativos (com uso de alguma fonte de energia), a adoção exclusiva de sistemas passivos permitiria atender a apenas $24 \%$ das condições de conforto térmico, sendo ainda mais complexo no caso dos espaços urbanos que são limitados em termos de estratégias ativas, que implicam em consumo energético e necessidade constante de manutenção.

Com base na análise dos dados climáticos pelo programa, são indicadas estratégias para Foz do Iguaçu de acordo com a Tabela 1, sendo que parte delas funcionam para a habitação e algumas podem ser aplicadas a projetos urbanos. Serão indicadas, portanto, com as letras H, estratégias para projetos de habitação e com $U$ para projetos urbanos e com $\mathrm{HU}$ as imagens que contemplem estratégias que possam ser aplicadas em ambos os casos.

Tabela 1. Detalhes das Estratégias indicadas para Foz do Iguaçu-PR

\begin{tabular}{|c|c|}
\hline $\mathrm{HU}$ & $\mathrm{H}$ \\
\hline $\begin{array}{l}\text { Estratégia 17: } \\
\text { Uso de vegetação (arbustos, árvores, paredes } \\
\text { cobertas de hera), especialmente no oeste para } \\
\text { minimizar o ganho de calor (priorizar o uso de } \\
\text { plantas nativas). }\end{array}$ & $\begin{array}{l}\text { Estratégia 25: } \\
\text { Em climas úmidos bem ventilados sótãos com } \\
\text { telhados inclinados funcionam bem para escoar a } \\
\text { chuva e pode ser estendidos para proteger entradas, } \\
\text { varandas e áreas de trabalho ao ar livre. }\end{array}$ \\
\hline HU & $\mathrm{H}$ \\
\hline $\begin{array}{l}\text { Estratégia 27: } \\
\text { Se o solo é úmido, elevar o edifício ou mobiliário } \\
\text { urbano acima do solo, para minimizar a umidade e } \\
\text { maximizar a ventilação natural debaixo dos edifícios } \\
\text { ou outros elementos. }\end{array}$ & $\begin{array}{l}\text { Estratégia 32: } \\
\text { Minimizar ou eliminar a envidraçados ou outros tipos } \\
\text { de superfícies transparentes a oeste de para reduzir } \\
\text { ganhos de calor no verão e outono à tarde. }\end{array}$ \\
\hline $\mathrm{HU}$ & $\mathrm{HU}$ \\
\hline $\begin{array}{l}\text { Estratégia 33: } \\
\text { Construções com plantas longas e estreitas podem } \\
\text { ajudar a maximizar a ventilação cruzada em climas } \\
\text { úmidos e quentes temperados. }\end{array}$ & $\begin{array}{l}\text { Estratégia 34: } \\
\text { Para capturar a ventilação natural, a direção do } \\
\text { vento pode ser alterada até } 45 \text { graus em direção ao } \\
\text { prédio por wingwalls (paredes inclinadas) exteriores } \\
\text { e vegetação. }\end{array}$ \\
\hline $\mathrm{H}$ & $\mathrm{HU}$ \\
\hline $\begin{array}{l}\text { Estratégia 35: } \\
\text { Uma boa ventilação natural pode reduzir ou eliminar } \\
\text { o ar condicionado no verão, se as janelas estiverem } \\
\text { à sombra e orientadas para brisas prevalecentes. }\end{array}$ & $\begin{array}{l}\text { Estratégia 36: } \\
\text { Para facilitar a ventilação cruzada, localizar aberturas } \\
\text { de portas e janelas em lados opostos do edifício, } \\
\text { com aberturas maiores viradas para cima ao captar } \\
\text { o vento, se possível. }\end{array}$ \\
\hline $\mathrm{HU}$ & $\mathrm{H}$ \\
\hline $\begin{array}{l}\text { Estratégia 37: } \\
\text { Brises horizontais (projetados para esta latitude) ou } \\
\text { outros tipos de dispositivos de proteção solar } \\
\text { operáveis (toldos que se estendem no verão) podem } \\
\text { reduzir ou eliminar uso do ar condicionado nos } \\
\text { espaços internos e favorecer o conforto térmico nos } \\
\text { externos. }\end{array}$ & $\begin{array}{l}\text { Estratégia 39: } \\
\text { Uma solução de ventilação que se aplique a toda a } \\
\text { casa (whole-house fan) ou ventilação natural pode } \\
\text { armazenar durante a noite em superfícies interiores } \\
\text { de alta massa (night flushing) para reduzir ou } \\
\text { eliminar o uso do ar condicionado. }\end{array}$ \\
\hline $\mathrm{H}$ & $\mathrm{H}$ \\
\hline $\begin{array}{l}\text { Estratégia } 42 \text { : } \\
\text { Em dias quentes ventiladores de teto ou de } \\
\text { movimento do ar interior pode fazê-lo parecer mais } \\
\text { frio } 2.8^{\circ} \mathrm{C} \text { ou mais, será necessário, portanto, menos } \\
\text { uso do ar condicionado. }\end{array}$ & $\begin{array}{l}\text { Estratégia 47: } \\
\text { Usar planos interiores abertos para promover a } \\
\text { ventilação cruzada natural ou usar portas com } \\
\text { persianas, ou dutos se a privacidade é necessária. }\end{array}$ \\
\hline
\end{tabular}

\begin{tabular}{|c|c|}
\hline HU & HU \\
\hline $\begin{array}{l}\text { Estratégia 49: } \\
\text { Para produzir ventilação com efeito chaminé, } \\
\text { mesmo quando a velocidade do vento é baixa, } \\
\text { maximizar a altura vertical entre a entrada e saída } \\
\text { de ar (escadarias abertas, espaços com pé direito } \\
\text { duplo, aberturas no telhado). }\end{array}$ & $\begin{array}{l}\text { Estratégia 53: } \\
\text { Zonas sombreadas ao ar livre (varandas, pátios) } \\
\text { orientadas para as brisas predominantes podem } \\
\text { estender as áreas para climas quentes ou úmidos. }\end{array}$ \\
\hline $\mathrm{H}$ & $\mathrm{H}$ \\
\hline
\end{tabular}

ACE, 15 (4.3) CC BY-ND 3.0 ES | UPC Barcelona, España | Análise de conforto urbano do marco das Três Fronteiras em Foz do Iguaçu-PR. DOI: http://dx.doi.org/10.5821/ace.15.43.8295 


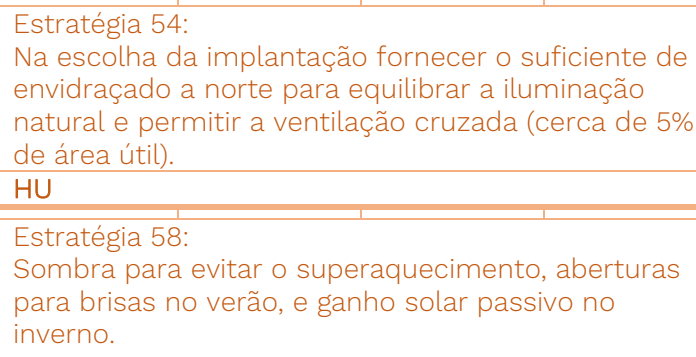

Fonte: Elaboração própria baseado no Climate Consultant 6.0, 2018.

Estratégia 56:
Varandas e pátios com tela podem fornecer
conforto passivo por meio do resfriamento
proporcionado por ventilação em dias quentes e
pode evitar problemas com insetos.
H
Estratégia 65:
Casas passivas tradicionais em climas quentes e
úmidos devem usar telhados altos e operáveis
(francês) e janelas altas protegidas por beirais
profundos e varandas.
profundos e varandas.

Os pontos 03 e 05 também apresentaram temperaturas semelhantes, o ponto 03 é próximo ao Mirante e o ponto 05 é próximo à lanchonete, com uma queda de temperatura em relação aos pontos 01 e 02 de cerca de 2ำ a partir das 14:00. As medições de temperaturas do ponto 04 foram as que mais oscilaram, principalmente de período da tarde, após as 14:00, trata-se do ponto mais próximo ao Marco das Três Fronteiras.

A vegetação do local possui a importante função na absorção e reflexão de parte da energia solar incidente. Assim, quando o grau de reflexão é maior (albedo, razão entre a quantidade de luz que é difundida ou refletida por uma superfície e a quantidade de luz incidente sobre a mesma), mais fria tende a ser a superfície. Em contrapartida, áreas mais abertas, com menor presença de vegetação, tendem a absorver mais energia solar, provocando o aumento das temperaturas. No entanto, conforme é observado (Figura 4a), as temperaturas são ligeiramente mais altas nas áreas vegetadas durante a tarde, o que ocorre devido a umidade relativa, que é mais elevada nas áreas vegetada, devido ao efeito de evapotranspiração das plantas. Como o vapor d'água é um eficiente absorvedor de energia de onda longa, emitida pela superfície, contribui para a redução da perda de calor da superfície, mantendo essas áreas mais aquecidas. Esse efeito é principalmente sentido no inverno, quando intensidade da radiação solar é menor.

A umidade relativa do ar é a relação entre a quantidade de água existente no ar (umidade absoluta) e a quantidade máxima que poderia haver na mesma temperatura (ponto de saturação). Significa basicamente, o quanto de água na forma de vapor existe na atmosfera no momento com relação ao total máximo que poderia existir, na temperatura observada. A umidade se eleva sempre que ocorrem chuvas, devido à evaporação que ocorre posteriormente; em áreas florestadas ou próximas aos rios ou outros corpos d'água ou ainda quando a temperatura diminui (orvalho).

A Figura 4b apresenta os resultados das medições dos valores da umidade relativa para os cinco pontos medidos. São apresentados os gráficos que apresentam as diferenças de umidade relativa de acordo com os pontos de medição para três horários: 9:00, 12:00 e 15:00.

Durante a manhã, os valores de umidade relativa observados foram os mais altos, devido às mais baixas temperaturas e foram diminuindo no decorrer da manhã. Em grande parte dos pontos, os valores continuaram em torno dos 50 a 60\%, isso a partir do meio dia, momento no qual as temperaturas se elevaram. A vegetação do entorno, os rios e a presença de lagos/reservatórios também explica a umidade elevada que é característica de Foz do Iguaçu.

Na cidade de Foz do Iguaçu, que apresenta umidade relativa elevada, o vapor de água presente no ar ajuda a reter calor. Em lugares mais secos, há menor retenção de calor na atmosfera e a diferença entre temperatura máxima e mínima é maior. Pode-se dizer que em locais como Foz do lguaçu é possível constatar muito calor durante o dia, graças ao Sol e mais frio à noite. A umidade tende a

ACE, 15 (4.3) CC BY-ND 3.0 ES | UPC Barcelona, España | Análise de conforto urbano do marco das Três Fronteiras 
reduzir o ciclo diurno, sendo que as noites deveriam ser mais amenas, pela menor perda radiativa à noite.

\subsection{Estudo de Caso no Marco das Três Fronteiras}

Para o desenvolvimento do estudo de caso das condições de conforto do Marco das Três Fronteiras, antes da revitalização, foram selecionados cinco pontos de medições, conforme explicado anteriormente na metodologia.

Devido ao período de abrangência da pesquisa e a disponibilidade do equipamento para realização de medições foi possível registrar os dados somente para o inverno. Foram coletados os dados de temperaturas e umidade relativa do ar no dia 21 de junho, solstício de inverno, nos horários de 8:00 as 17:00

\subsubsection{Temperaturas e Umidade Relativa do Ar nos Pontos Analisados}

As temperaturas observadas nos pontos de medição apresentam-se coerentes para os horários e com elevação de temperatura esperada para o período após 12 h00 (Figura 4a). Esse resultado sugere a redução do ciclo diurno pela umidade, sendo que normalmente em locais mais secos a máxima é atingida por volta das $15 \mathrm{~h}$. Os pontos 01 e 02 apresentam temperaturas bem semelhantes, sendo o ponto 01, próximo ao parque infantil e o 02, próximo aos bancos (assentos) nos quais os visitantes se sentam, sendo que ambos são os mais afastados da margem do rio. Tais pontos apresentam as temperaturas mais elevadas dentre os demais pontos considerados.

Os pontos 03 e 05 também apresentam temperaturas semelhantes, o ponto 03 é próximo ao antigo mirante e o ponto 05 é próximo à uma lanchonete (área de alimentação) existente na época, com uma queda de temperatura em relação aos pontos 01 e 02 de cerca de $2^{\circ} \mathrm{C}$ a partir das 14:00. As medições de temperatura do ponto 04 foram as que mais oscilaram, principalmente de período da tarde, após as 14:00. Apesar das medições terem ocorrido no inverno, isso é um fator que incomodava os visitantes igualmente no verão, principalmente, pois esse ponto próximo ao Marco das Três Fronteiras é o principal onde os visitantes permaneciam durante boa parte do tempo.

$\mathrm{Na}$ Figura 4a seguem os gráficos que apresentam as diferenças de temperatura de acordo com os pontos de medição para três horários: 9:00, 12:00 e 15:00. Durante a manhã observou-se uma temperatura mais baixa cerca de $19^{\circ} \mathrm{C}$ nos pontos próximos à vegetação (pontos 01 e 02 ). A medida que se aproxima do Marco das Três Fronteiras a temperatura se eleva (pontos 03, 04 e 05). Para os horários da tarde 12:00 e 15:00 observou-se uma temperatura ligeiramente mais elevada, cerca de 27 a $28^{\circ} \mathrm{C}$ nos pontos próximos à vegetação (pontos 01, 02) e a medida que se aproxima do Marco (pontos 03, 04 e 05) a temperatura sofre uma pequena diminuição. Os pontos 01 e 02 apresentam temperaturas bem semelhantes. O ponto 01, próximo ao parque infantil e o 02, próximo aos bancos, sendo que esses pontos são os mais afastados da margem do rio. Tais pontos apresentam as temperaturas mais elevadas dentre os demais pontos medidos durante a tarde A Figura 4 a-b apresenta as temperaturas (a) e umidade relativa do ar (b) nos pontos analisados.

Figura 4. Temperatura nos pontos de medição - 21 de junho: Temperatura às 9:00, às 12:00 e às 15:00 (a); Umidade relativa nos pontos de medição: às 9:00, às 12:00 e às 15:00 (b) em Foz do Iguaçu-PR. DOI: http://dx.doi.org/10.5821/ace.15.43.8295 


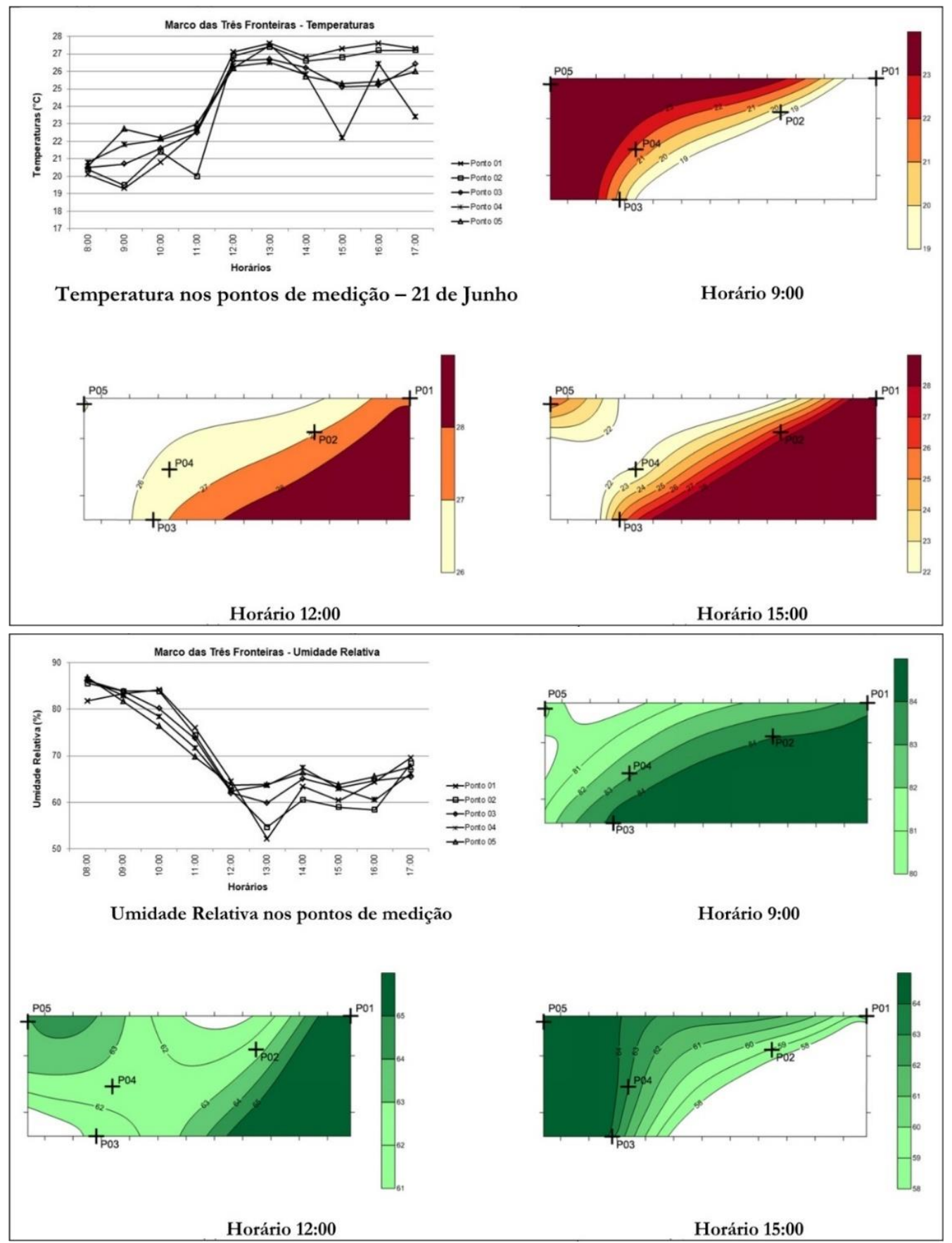

Fonte: Elaboração própria.

Os pontos 03 e 05 também apresentaram temperaturas semelhantes, o ponto 03 é próximo ao Mirante e o ponto 05 é próximo à lanchonete, com uma queda de temperatura em relação aos pontos 01 e 02 de cerca de 2ำ a partir das 14:00. As medições de temperaturas do ponto 04 foram as que mais oscilaram, principalmente de período da tarde, após as 14:00, trata-se do ponto mais próximo ao Marco das Três Fronteiras.

A vegetação do local possui a importante função na absorção e reflexão de parte da energia solar incidente. Assim, quando o grau de reflexão é maior (albedo, razão entre a quantidade de luz que é difundida ou refletida por uma superfície e a quantidade de luz incidente sobre a mesma), mais fria

ACE, 15 (4.3) CC BY-ND 3.0 ES | UPC Barcelona, España | Análise de conforto urbano do marco das Três Fronteiras 14 em Foz do Iguaçu-PR. DOI: http://dx.doi.org/10.5821/ace.15.43.8295 
tende a ser a superfície. Em contrapartida, áreas mais abertas, com menor presença de vegetação, tendem a absorver mais energia solar, provocando o aumento das temperaturas. No entanto, conforme é observado (Figura 4a), as temperaturas são ligeiramente mais altas nas áreas vegetadas durante a tarde, o que ocorre devido a umidade relativa, que é mais elevada nas áreas vegetada, devido ao efeito de evapotranspiração das plantas. Como o vapor d'água é um eficiente absorvedor de energia de onda longa, emitida pela superfície, contribui para a redução da perda de calor da superfície, mantendo essas áreas mais aquecidas. Esse efeito é principalmente sentido no inverno, quando intensidade da radiação solar é menor.

A umidade relativa do ar é a relação entre a quantidade de água existente no ar (umidade absoluta) e a quantidade máxima que poderia haver na mesma temperatura (ponto de saturação). Significa basicamente, o quanto de água na forma de vapor existe na atmosfera no momento com relação ao total máximo que poderia existir, na temperatura observada. A umidade se eleva sempre que ocorrem chuvas, devido à evaporação que ocorre posteriormente; em áreas florestadas ou próximas aos rios ou outros corpos d'água ou ainda quando a temperatura diminui (orvalho).

A Figura 4b apresenta os resultados das medições dos valores da umidade relativa para os cinco pontos medidos. São apresentados os gráficos que apresentam as diferenças de umidade relativa de acordo com os pontos de medição para três horários: 9:00, 12:00 e 15:00.

Durante a manhã, os valores de umidade relativa observados foram os mais altos, devido às mais baixas temperaturas e foram diminuindo no decorrer da manhã. Em grande parte dos pontos, os valores continuaram em torno dos 50 a 60\%, isso a partir do meio dia, momento no qual as temperaturas se elevaram. A vegetação do entorno, os rios e a presença de lagos/reservatórios também explica a umidade elevada que é característica de Foz do Iguaçu.

Na cidade de Foz do Iguaçu, que apresenta umidade relativa elevada, o vapor de água presente no ar ajuda a reter calor. Em lugares mais secos, há menor retenção de calor na atmosfera e a diferença entre temperatura máxima e mínima é maior. Pode-se dizer que em locais como Foz do Iguaçu é possível constatar muito calor durante o dia, graças ao Sol e mais frio à noite. A umidade tende a reduzir o ciclo diurno, sendo que as noites deveriam ser mais amenas, pela menor perda radiativa à noite.

\subsection{Análise Global}

Tendo por base a medição de temperaturas durante o inverno, pela manhã, observa-se uma temperatura mais baixa nos pontos próximos à vegetação (pontos 01 e 02). A medida que se aproxima do Marco das Três Fronteiras, a temperatura se eleva (pontos 03, 04 e 05). Durante à tarde, no inverno, observou-se uma temperatura ligeiramente mais elevada, nos pontos próximos à vegetação (pontos 01 e 02) e à medida que se aproxima do Marco das Três Fronteiras (Pontos 03, 04 e 05) a temperatura sofre uma pequena diminuição (Figura 15).

Em resumo, tem-se: Ponto 01: Próximo ao antigo parque das crianças - temperaturas mais baixas durante a manhã e mais elevadas durante à tarde; Ponto 02: Próximo aos bancos destinados aos visitantes - temperaturas mais baixas durante a manhã e mais elevadas durante à tarde; Ponto 03: Próximo ao mirante - temperatura mais elevada durante a manhã e uma pequena diminuição à tarde; Ponto 04: Próximo ao Marco das Três Fronteiras - temperatura mais elevada durante a manhã e uma pequena diminuição à tarde; Ponto 05: Próximo à antiga lanchonete - temperatura mais elevada durante a manhã e uma pequena diminuição à tarde.

ACE, 15 (4.3) CC BY-ND 3.0 ES | UPC Barcelona, España | Análise de conforto urbano do marco das Três Fronteiras em Foz do Iguaçu-PR. DOI: http://dx.doi.org/10.5821/ace.15.43.8295 
A oscilação das temperaturas, principalmente de período da tarde, após as 14:00, é um fator que incomoda os visitantes mesmo durante o inverno. Mesmo com a realização das medições durante o solstício de inverno, foram observadas temperaturas elevadas, sendo assim pode-se supor durante o verão o desconforto que ocorre no local deve ser bem superior.

Ao comparar os gráficos das temperaturas com a umidade relativa percebe-se que na medida em que a temperatura aumenta ao longo do dia, a umidade relativa decresce. Fazendo um paralelo entre a temperatura e a umidade tem-se que: temperaturas mais elevadas são acompanhadas de umidade mais baixa e menores temperaturas de maiores valores de umidade. Durante a noite, a tendência será que a vegetação próxima funcione como um anteparo às perdas radiativas, o que não ocorre em áreas sem vegetação, sendo o resfriamento noturno intensificado.

\subsection{Propostas de Estratégias Bioclimáticas para melhorar as condições de conforto do local}

Tendo por base a medição de temperaturas durante o inverno, pela manhã, observa-se uma temperatura mais baixa nos pontos próximos à vegetação (pontos 01 e 02). A medida que se

Nessa etapa foram indicadas algumas estratégias que possam minimamente melhorar as condições de conforto do local para os habitantes do entorno e turistas que frequentam o Marco das Três Fronteiras na época. Analisando a temperatura, umidade, radiação solar, movimento do ar e precipitações, tem-se a base para propor soluções na tentativa de amenizar as condições do microclima local. Para tal, indica-se:

- O aproveitamento do fluxo do ar das correntes dominantes, já que nesse tipo de clima a umidade é elevada, porém a proposta deve ser criar espaços orientados favoravelmente às correntes de ar predominantes, de forma a proporcionar o resfriamento do local;

- Devido às altas temperaturas observadas no verão, a presença de vegetação produz sombra no espaço público, e, além disso, recomenda-se que sejam previstos espaços verdes nos projetos de forma a auxiliar na absorção de radiação e proporcionar ambiente mais confortável, no caso do Marco das Três Fronteiras a inexistência de sombreamento nos principais pontos é um elemento desfavorável no local;

- Essa região tem por natureza a constante precipitação nos diferentes meses do ano, por isso indica-se a criação de espaços com abrigos para o público nos momentos de chuva;

- Recomenda-se ainda a utilização de cores claras para as construções e demais elementos, próximos ao Marco das Três Fronteiras, tendo em vista que cores mais claras apresentam menor absorção e maior índice de reflexão da radiação incidente.

Com base nos resultados do software Climate Consultant 6.0, tem-se como adaptar as principais recomendações para projetos urbanos inseridos no clima de Foz do Iguaçu-PR:

- Uso de vegetação (arbustos, árvores, paredes cobertas de hera), especialmente no Oeste para minimizar o ganho de calor (se as chuvas de verão apoiar o crescimento da planta nativa);

- Se o solo é úmido, elevar construções e utilizar mobiliário urbano permeável, acima do solo para minimizar a umidade e maximizar a ventilação natural;

- Para capturar a ventilação natural, a direção do vento pode ser alterada até 45 graus em direção ao local onde deve incidir; Brises horizontais (projetados para esta latitude) ou outros tipos de dispositivos de proteção solar operáveis (toldos que se estendem no verão) podem amenizar a sensação de calor;

- Para produzir ventilação com efeito chaminé, mesmo quando a velocidade do vento é baixa, maximizar a altura vertical entre a entrada e saída de ar entre elementos urbanos;

ACE, 15 (4.3) CC BY-ND 3.0 ES | UPC Barcelona, España | Análise de conforto urbano do marco das Três Fronteiras em Foz do Iguaçu-PR. DOI: http://dx.doi.org/10.5821/ace.15.43.8295 
- Zonas sombreadas ao ar livre devem ser orientadas para as brisas predominantes podem estender as áreas para climas quentes ou úmidos; Sombra para evitar o superaquecimento, aberturas para brisas no verão, e ganho solar passivo no inverno.

\subsection{Situação Atual do Marco das Três Fronteiras}

Em dezembro de 2015, após a realização das medições do presente pequisa (em junho) foi entregue uma primeira fase de revitalização da área do Marco das Três Fronteiras, que passou a ser denominado de Complexo Turístico Marco das Américas e que integra, além do Marco das Três Fronteiras, um Centro de Visitantes, uma área de estacionamentos e um boteco (área de alimentação), criando uma utilização noturna para o espaço. Futuramente, será agregado ao complexo o Espaço das Américas. Isso confirma os problemas de falta de infraestrutura que ocorriam no local, mas que felizmente estão sendo amenizados. Porém, cabe a uma pesquisa futura, verificar a influência de tal revitalização nas condições de conforto urbano. Vale mencionar ainda, que apesar das melhorias realizadas no local, o espaço atual tem seu acesso controlado e não é mais gratuito aos não residentes na cidade de Foz de Iguaçu. A revitalização executada condiz mais com a função turística do local, do que com a afirmação da identidade do marco como importante elemento histórico da cidade de um dos principais símbolos da região de Foz do Iguaçu, ou seja, percebe-se que mesmo tendo ocorrido uma melhoria nas condições de infraestrutura e conforto urbano, a revitalização atendeu primordialmente a interesses turísticos, perdendo a sua identidade em termos arquitetônicos e urbanísticos.

\subsection{Estratégias Bioclimáticas para Projetos Urbanos em Foz do Iguaçu}

Não há diretrizes específicas para projetos urbanos nas normas e regulamentos no Brasil, porém a proposição de estratégias está condicionada à análise das características geomorfológicas da região e deve ser feita com base no estudo do clima. Tendo em vista que se trata de um local de clima subtropical úmido, as estratégias para projetos urbanos mais sustentáveis devem respeitar critérios específicos, pois essas regiões são caracterizadas por verões quentes e temperaturas baixas durante o inverno. A análise do microclima também vai influenciar na estratégia a ser adotada, considerando a presença de corpos d’água e vegetação no local.

No caso de climas subtropical úmido, a estratégia principal deve ser a diminuição da temperatura, por meio do incremento do movimento do ar, impedimento a absorção da umidade e as formas (obstáculos) devem ser dispersas para permitir ventilação. Diante disso, a principal recomendação é em relação à ventilação natural; por exemplo, criar amplos espaços entre os edifícios ou elementos urbanos, projetar ruas e avenidas com um traçado regular para facilitar a circulação de ar. Devido às altas temperaturas observadas no verão, a presença de vegetação produz sombra no espaço público, e, além disso, recomenda-se que sejam previstos espaços verdes nos projetos de forma a auxiliar na absorção de radiação e criar ambiente mais confortável. Um grande problema no caso de Foz do Iguaçu é a elevada umidade relativa do ar (superior a $75 \%$ na maior parte do ano, atingindo valores elevados entre o outono e o inverno, chegando a $86 \%$ em maio), que proporciona condições de desconforto ainda maiores.

Segundo Romero (2000), a localização deve dar-se em termos de orientação, na direção dos ventos dominantes que é o elemento preponderante para clima quente e úmido. As ruas devem oferecer espaços ensolarados e sombreados acompanhados de vegetação. Os terrenos devem ter vedações de preferência naturais e o alinhamento das edificações não deve ser rígido. Os espaços abertos devem prevalecer, e ser arborizados, permitindo a ventilação que auxilia nos espaços construídos. Com base no estudo de caso realizado e na análise de clima adaptada proveniente do programa Climate Consultant pode-se indicar como principais estratégias para o clima de Foz do Iguaçu:

ACE, 15 (4.3) CC BY-ND 3.0 ES | UPC Barcelona, España | Análise de conforto urbano do marco das Três Fronteiras 17 em Foz do Iguaçu-PR. DOI: http://dx.doi.org/10.5821/ace.15.43.8295 
- Incremento da ventilação natural, mesmo que as trocas sejam menores, aproveitando o fluxo do ar das correntes dominantes, se for possível, criar alguma alternativa para a diminuição da umidade do ar;

- Utilização de vegetação para sombreamento nos espaços públicos (arbustos, árvores, paredes verdes, telhados verdes, etc, especialmente no Oeste) e, além disso, e absorção de radiação;

- Utilização de espaços com abrigos nas áreas públicas, para proteção, além da radiação, nos períodos de chuvas que são frequentes;

- Uso de cores claras nos elementos da paisagem urbana, para uma menor absorção e maior índice de reflexão da radiação incidente;

- Elevação de elementos urbanos e construções, de forma a torná-los permeáveis, minimizar a umidade e maximizar a ventilação natural;

- Utilização de elementos de proteção solar nos espaços urbanos, sejam elementos naturais ou construídos.

\section{Conclusões}

Com a caracterização de estratégias bioclimáticas aplicadas a projetos urbanos foi possível: Estudar o clima de Foz do Iguaçu e entender sua relação com a elaboração de projetos urbanos; Elaborar um levantamento de estratégias bioclimáticas (passivas) com potencial de aplicação em projetos urbanos inseridos no clima de Foz do Iguaçu-PR; Verificar o rigor do clima quente e úmido, que caracteriza um grande desconforto térmico e dificulta a adoção de soluções passivas; Obter as características necessárias para projetos urbanos que impliquem em melhor conforto térmico, possibilitando a arquitetos e engenheiros a escolha de soluções adequadas ao clima de Foz do Iguaçu, durante o processo de projeto de novas intervenções e revitalização de espaços urbanos já existentes.

Os resultados da pesquisa revelam a importância do estudo do clima para a determinação de soluções para projetos urbanos, identificando problemas e indicando soluções para o caso específico de Foz do Iguaçu. Vale salientar que diante do rigor do clima de Foz do Iguaçu-PR, que apresenta temperaturas elevadas no verão e mais baixas no inverno, o uso exclusivo de sistemas passivos, permitiria atender a apenas $24 \%$ das condições de conforto térmico para construções. Portanto, para projetos urbanos as condições podem ser ainda mais agravantes, dada a restrição de uso de sistemas ativos para resfriamento e aquecimento.

\section{Agradecimientos}

Os autores agradecem ao Conselho Nacional de Desenvolvimento Científico e Tecnológico (CNPq), pelo suporte financeiro para o desenvolvimento do presente estudo.

\section{Autoria}

Helenice M. Sacht foi responsável pela idealização, coordenação da pesquisa e desenvolvimento do artigo; Herlander Mata-Lima realizou a atualização do conteúdo, referências e revisão do texto em geral; Andrea de Oliveira Cardoso fez a revisão de todas as análises de dados e tópicos relacionados ao estudo do clima e Jair Stivenz C. Delgado realizou as medições para o estudo de caso in loco no Marco das Três Fronteiras.

ACE, 15 (4:3) CC BY-ND 3.0 ES | UPC Barcelona, España | Análise de conforto urbano do marco das Três Fronteiras em Foz do Iguaçu-PR. DOI: http://dx.doi.org/10.5821/ace.15.43.8295 
Conflito de interesses: Os autores declaram que não há conflito de interesses.

\section{Bibliografía}

Alvares, C. A.; Stape, J.L.; Sentelhas, P. C.; Moraes Gonçalves, J. L. e Sparovek, G. (2014) Köppen's climate classification map for Brazil. Meteorologische Zeitschrift, 22(6), 711-728. DOI: https://dx.doi.org/10.1127/0941-2948/2013/0507

Arellano B.; Roca, J. e Batlle, E. (2018). Green areas and urban heat island: combining remote sensed data with ground observations. In Proceedings SPIE 10767. Remote Sensing and Modeling of Ecosystems for Sustainability XV, SPIE Optical Engineering + Applications, 2018 (1076705). San Diego, California, United States. DOI: https://doi.org/10.1117/12.2320999

Assis, E. S. (2006). Aplicações da climatologia urbana no planejamento da cidade: revisão dos estudos brasileiros. Revista de Urbanismo e Arquitetura, 1 (9): 20-25. Recuperado de: https://portalseer.ufba.br/index.php/rua/article/view/3149/2261

Associação Brasileira de Normas Técnicas (ABNT). (2005). NBR 15220-3: Desempenho térmico de edificações. Parte 3 Zonemento Bioclimático. Rio de Janeiro.

Climate Consultant 6.0. (2019) Energy Design Tools, Recuperado de: http://www.energy-designtools.aud.ucla.edu/climate-consultant/request-climate-consultant.php

Duarte, D.; Shinzato, P.; Gusson, C. S. e Alves, C. A. (2015). The impact of vegetation on urban microclimate to counterbalance built density in a subtropical changing climate. Urban Climate, 14: 224-239. DOI: https://doi.org/10.1016/j.uclim.2015.09.006

Ferreira, L. F.; Carrilho, S. T. e Mendes, P. C. (2015). Áreas verdes urbanas: uma contribuição aos estudos das ilhas de frescor. Brazilian Geographical Journal: Geosciences and Humanities research médium, 6(2), 101-120. Recuperado de: http://www.seer.ufu.br/index.php/braziliangeojournal/article/view/30309/18023

Flor, F. S. e Domínguez, S. A. (2004). Modelling microclimate in urban environments and assessing its influence on the performance of surrounding buildings. Energy and Buildings, 36: 403-413. DOI: http://dx.doi.org/10.1016/j.enbuild.2004.01.050

Garcia-Haro, A. e Arellano, B. (Septiembre, 2018) Isla de frío de los parques urbanos de Barcelona. Estudio de caso del Turó parc y el parc del Centre del Poblenou. En: Libro de proceedings, CTV 2018: XII Congreso Internacional Ciudad y Territorio Virtual: "Ciudades y Territorios Inteligentes"(p. 381-400). UNCuyo, Mendoza. Barcelona: CPSV. DOI: http://dx.doi.org/10.5821/ctv.8253

Gomez, F.; Gil, L. e Jabaloyes, J. (2004). Experimental investigation on the thermal comfort in the city: relationship with the green areas, interation with the urban microclimate. Building and Environment, 39(9): 1077-1088. DOI: https://doi.org/10.1016/j.buildenv.2004.02.001

Gomez, F.; Tamarit, N. e Jabaloyes, J. (2001). Green zones, bioclimatics studies and human comfort in the future development of urban planning. Landscape and Urban Planning, 55: 151-161. DOI: https://doi.org/10.1016/S0169-2046(01)00150-5

Higueras, E. (2006). Urbanismo bioclimatico. Ed Gustavo Gili. Barcelona.

Katzschner, L. (1997). Urban climate studies as tools for urban planning and architecture. En: Anais do IV ENCAC (p. 49-58). Salvador, FAUFBA, ANTAC.

ACE, 15 (4.3) CC BY-ND 3.0 ES | UPC Barcelona, España | Análise de conforto urbano do marco das Três Fronteiras em Foz do Iguaçu-PR. DOI: http://dx.doi.org/10.5821/ace.15.43.8295 
Kapsomenakis, J.; Kolokotsab, D.; Nikolaouc, T.; Santamourisd, M. e Zerefose, S.C. (2013). Forty years increase of the air ambiente temperature in Greece: The impact on buildongs. Energy Conversion and Management, 74, 353-365. DOI: http://dx.doi.org/10.1016/j.enconman.2013.05.005

Maia, M. R.; Siqueira Pinto, J. E. S. e Lima, E. M. (2017). Eventos pluviométricos extremos na cidade de Vitória da Conquista (BA) entre 1995 e 2015. Revista GeoNordeste, 2, 42-55. Recuperado de: https://seer.ufs.br/index.php/geonordeste/article/view/6273/pdf

Marincic, I.; Ochoa, J. M. e Río, J. A. (2012). Confort térmico adaptativo dependiente de la temperatura y la humedad. ACE: Architecture, City and Environment. 7(20), 27-46. DOI: http://dx.doi.org/10.5821/ace.v7i20.2572

Martini, A.; Biondi, D.; Viezzer, J. e \& Silva, D. (2015). O efeito microclimático do fragmento florestal existente no Parque Municipal do Barigui na cidade Curitiba-PR. Ciência e Natura, 37, 125-131. DOI: http://dx.doi.org/10.5902/2179460X16227

Monteiro, C. A. F. (1976). Teoria e Clima Urbano. São Paulo, IGEOG/USP.

Moonen, P.; Defraeyec, T.; Dorerb, V.; Blockend, B. e Carmelietab, J. (2012). Urban Physics: Effect of the micro-climate on comfort, health and energy demand. Frontiers of Architectural Research, 1(3), 197-228. DOI: http://dx.doi.org/10.1016/j.foar.2012.05.002

Musy, M.; Malys, L. M.; Morille, B. e Inard, C. (2015). The use of SOLENE-microclimate model to assess adaptation strategies at the distric scale. Urban Climate, 14(2), 213-223. DOI: https://doir.org/10.1016/j.uclim.2015.07.004

Olgyay, V. Design with Climate. New Jersey: Princeton University Press, 1963.

Romero, M. A. B. (2000). Princípios bioclimáticos para o desenho urbano. 2. ed. São Paulo: Pro Editores.

Romero, M. A. B. (2007). Arquitetura Bioclimática do Espaço Público. Brasília: Editora UnB.

Saeed, E.; Azmy, N. e Omar, N. (2018). The role of the landscape elements to improve the urban spaces environmental performance. ACE: Architecture, City and Environment, 12(36), 91-110. DOI: http://dx.doi.org/10.5821/ace.12.36.4851

Salvati, A.; Coch Roura, H. e Cecere, C. (2016). Urban heat island prediction in the mediterranean context: an evaluation of the urban weather generator model. ACE: Architecture, City and Environment, 11 (32), 135-156, 2016. DOI: http://dx.doi.org/10.5821/ace.11.32.4836

Santos, J. C. (2015). Uma leitura micro da tríplice fronteira Brasil, Paraguai e Argentina. In: XXVIII Simpósio Nacional de História. Florianópolis. Recuperado de: http://www.snh2015.anpuh.org/resources/anais/39/1433683866 ARQUIVO Textofinal2015.pdf

Toparlar, Y.; Blocken, B.; Maiheu, B., \& Van Heijst, G.J.F. (2017). The effect of an urban park on the microclimate in its vicinity: a case study for Antwerp, Belgium. International Journal of Climatology. Recuperado de: https://rmets.onlinelibrary.wiley.com/doi/epdf/10.1002/joc.5371

Unger, J. (1995). Some aspects of the human bioclimate of a medium-sized town and its surroundings. In: Climatology and Air Pollution Conference. Mendoza, Argentina, p. 41-49.

Vemado, F. e Pereira Filho, A. J. (2016). Severe Weather Caused by Heat Island and Sea Breeze Effects in the Metropolitan Area of São Paulo, Brazil. Advances in Meteorology, 3, 1-13. DOI: http://dx.doi.org/10.1155/2016/8364134

Yang, X. e Li, Y. The impact of building density and building height heterogeneity on average urban albedo and street surface temperatura. Building and Environment, vol. 90, pp. 146-156 DOI: https://doi.org/10.1016/j.buildenv.2015.03.037

ACE, 15 (4.3) CC BY-ND 3.0 ES | UPC Barcelona, España | Análise de conforto urbano do marco das Três Fronteiras em Foz do Iguaçu-PR. DOI: http://dx.doi.org/10.5821/ace.15.43.8295 